\title{
The patient knows best: a new self-reported outcome measure for systemic sclerosis
}

\author{
K.E.N. Clark and C.P. Denton \\ Centre for Rheumatology and Connective Tissue Diseases, UCL Division of \\ Medicine, London, UK Correspondence: Christopher Denton. Email: c.denton@ucl.ac.uk
}

Patient-reported outcome measures (PROMs) document the impact of a health condition judged by the patient, not through a clinician. An effective PROM requires construct and content validity, reliability and accuracy, as well as the ability to capture change over time for the clinical condition.

Systemic sclerosis (SSc) is a multifaceted disease with high morbidity and mortality. As such, development of a reliable PROM to assess morbidity has been challenging, given the many different ways in which patients are affected. Physicians tend to focus on the extent of skin involvement (assessed by modified Rodnan skin score, MRSS)1 or organ manifestations; however, these are often not the aspects of the disease that are of most concern to patients. For example, approximately half of patients end up unable to work as a result of SSc. 2 Previous work by Pauling et al. reviewed different PROMs utilized in SSc research. They found that only $21 \%$ of the PROMs used were developed specifically for SSc, and of these, less than $50 \%$ included significant patient involvement in their develop- ment. 3 This is a major limitation because subjective worsening or improvement judged by patients is critical and should reflect the impact and symptoms in a disease-specific way. 4

Although studies have shown that survival is associated with severity of clinical parameters such as lung function, or MRSS, other nonlethal symptoms are often not captured and psychosocial aspects of the disease are underappreciated. Fatigue is one of the aspects of the disease, reported by up to $90 \%$ patients, with pain affecting $80 \%$ of patients during the disease course. Global assessments have shown large differences between how physicians and patients rate severity. 5 With cur- rent therapy, patients are now living longer with SSc, 6 and targeting the psychosocial and nonlethal aspects of the disease, as well as organ complications, will be essential to improve quality of life.

In this issue of the BJD, Daste et al. present a new PROM: the Cochin 17-item Scleroderma Functional scale, focusing on mobility and impact on cognitive function and complex tasks.7 Patient involvement has been central to its development. Prelim-inary validation suggests that it is able to differentiate between the diffuse and limited forms of SSc, not usually appreciated in PROMs. Moreover, it had high correlation with HAQ (Health Assessment Questionnaire) and SHAQ (Scleroderma HAQ), and has proved reliable in a test-retest exercise.

SHAQ incorporates visual analogue scores of the impacts of pain, digital ulcers and organ manifestation on the patient, as well as addressing mobility and upper-limb function by incorporating the HAQ Disability Index (HAQ-DI), calculated without physical aids. However, SHAQ is heavily dependent on a tool developed for arthritis and is often improperly scored, making interpretation of results difficult. It correlates with long-term outcome in SSc8 and may show improvement after treatments such as autologous stem cell transplantation, 9 but it is not disease specific. A feasible global measure is required, and, once fully validated, the Cochin 17-item Scleroderma Functional scale has real potential as a new PROM for clinical 
trials and practice.

\section{References}

1 Khanna D, Furst DE, Clements PJ et al. Standardization of the modi- fied Rodnan skin score for use in clinical trials of systemic sclerosis. J Scleroderma Relat Disord 2017; 2:11-18. 2 Ouimet JM, Pope JE, Gutmanis I, Koval J. Work disability in sclero- derma is greater than in rheumatoid arthritis and is predicted by high HAQ scores. Open Rheumatol J 2008; 2:44-52.

3 Pauling JD, Frech TM, Domsic RT, Hudson M. Patient participation in patientreported outcome instrument development in systemic sclerosis. Clin Exp Rheumatol 2017; 35 (Suppl. 106):184-92.

4 Ross L, Stevens W, Wilson M et al. Can patient-reported symptoms be used to measure disease activity in systemic sclerosis? Arthritis Care Res 2020; https://doi.org/10.1002/acr.24053.

5 Pellar RE, Tingey TM, Pope JE. Patient-reported outcome measures in systemic sclerosis (scleroderma). Rheum Dis Clin North Am 2016; 42:301-16.

6 Nihtyanova SI, Tang EC, Coghlan JG et al. Improved survival in sys- temic sclerosis is associated with better ascertainment of internal organ disease: a retrospective cohort study. QJM 2010; 103:109-15.

7 Daste C, Abdoul H, Foissac F et al. Development of a new patient- reported outcome measure to assess activities and participation in people with systemic sclerosis: the Cochin 17-item Scleroderma Functional scale. Br J Dermatol 2020; https://doi.org/10.1111/bjd. 18922.

8 Sultan N, Pope JE, Clements PJ. The Health Assessment Question- naire (HAQ) is strongly predictive of good outcome in early diffuse scleroderma: results from an analysis of two randomized controlled trials in early diffuse scleroderma. Rheumatology (Oxford) 2004; 43:472-8.

$9 \quad$ Puyade M, Maltez N, Lansiaux P et al. Health-related quality of life in systemic sclerosis before and after autologous haematopoietic stem cell transplant - a systematic review. Rheumatology (Oxford) 2020; https://doi.org/10.1093/rheumatology/kez300. 